\title{
MộT Số YẾU TỐ LIÊN QUAN ĐẾN CHẢY MÁU 24 GIỜ SAU ĐẺ ĐƯỜNG ÂM ĐẠO TẠI BÊ̂NH VIÊ̂N PHỤ SẢN HÀ NộI
}

\section{TÓM TẮT}

Mục tiêu: Xác định một số yếu tố liên quan đến chảy máu 24 giờ sau đẻ đường âm đạo tại bệnh viện Phụ sản Hà Nội 2019 - 2020. Đối tượng nghiển cứu: Tất cả các sản phụ được chẩn đoán CMSĐ 24h đường âm đạo được chẩn đoán, điều trị tại BVPSHN từ ngày $1 / 1 / 2019-31 / 12 / 2020$ đáp ứng tiêu chuẩn lựa chọn. Kết quả: Tỷ lệ chảy máu sau đẻ 24 giờ đường âm đạo tại Bệnh viện Phụ sản Hà Nội năm 2019 là 0,3 $\%$, giảm xuống 0,26\% trong năm 2020, tỷ lệ chung trong 2 năm là $0,28 \%$. Tỷ lệ sản phụ sinh con rạ có chảy máu sau đẻ cao hơn gẩp 2 lần sản phụ sinh con so. Số sản phụ có thai nhi từ $3500 \mathrm{gr}$ trở xuống chiếm tỷ lệ CMSĐ cao hơn số sản phụ có thai nhi trên 3500 gram. Thời điểm chảy máu sau đẻ hay gặp nhất $0-2 \mathrm{~h}$ chiếm khoảng 95\%. Kết luân: Tuổi thai, số lần sinh con và thời điểm chảy máu sau đẻ đều là những yếu tố liên quan đến tình trạng chảy máu sau đẻ ở sản phụ.

Tư khóa: chảy máu sau đẻ, tuổi thai, số lần sinh con

\section{SUMMARY}

\section{FACTORS RELATED TO EARLY POSTPARTUM HEMORRHAGE AFTER VAGINAL BIRTH AT HANOI OBSTETRICS \& GYNECOLOGY HOSPITAL}

Purpose: To determine several factors related to early postpartum hemorrhage after vaginal birth at Hanoi obstetrics and gynecology hospital from January 2019 to December 2020. Subjects and methods: All women diagnosed with postpartum hemorrhage within 24 hours after vaginal delivery and treated at Hanoi obstetrics and gynecology hospital from January 1, 2019 to December 31, 2020, meeting the selection criteria. Results: The rate of postpartum hemorrhage of women after 24 hours delivery at Hanoi Obstetrics and Gynecology Hospital in 2019 was $0.3 \%$, decreased to $0.26 \%$ in 2020 , the overall rate in 2 years was $0.28 \%$. The rate of postpartum hemorrhage in women with second or more pregnancy was 2 times higher than that of women first time giving birth. The number of women having a fetus of 3500 grams or less accounted for a higher percentage of postpartum hemorrhage than ones having a fetus over 3500 grams. The most common postpartum hemorrhage time is 0-2 hours, accounting for about $95 \%$. Conclusion: Gestational age, number of births and time of postpartum hemorrhage are several factors related to hemorrhage in postpartum women.

\section{*Bệnh viện Phụ sản Hà Nội}

Chịu trách nhiệm chính: Nguyễn Duy Ánh

Email: bsanhbnhn@yahoo.com

Ngày nhận bài: 15.9.2021

Ngày phản biện khoa học: 12.11.2021

Ngày duyệt bài: 22.11.2021

\section{Nguyễn Duy Ánh*, Nguyễn Đình Quynh*}

Keywords: postpartum hemorrhage, gestational age, number of births

\section{I. ĐẶT VẤN ĐỀ}

Chảy máu sau đẻ (CMSĐ) là một trong 5 tai biến sản khoa, đứng đầu trong các nguyên nhân gây tử vong me. Theo Tổ chức $\mathrm{Y}$ Tế Thế Giới hàng năm có khoảng 13.795.000 bà mẹ bị CMSÐ và khoảng 132.000 trường hợp chết mẹ liên quan trực tiếp đến $\mathrm{CMS}^{6}$. Tại Việt Nam: Tư vong do chảy máu sau đẻ chiếm tỷ lệ cao nhất trong số các nguyên nhân tử vong mẹ. Ở Viện bảo vệ bà mẹ trẻ sơ sinh (BVBMTSS) 1996 2000 , tỷ lệ tử vong do CMSĐ chiếm $27,5 \%$ trong số các trường hợp tử vong $\mathrm{me}^{4}$. Có nhiều nguyên nhân có thể gây nên CMSĐ như: đờ TC, sót rau, chấn thương đường sinh dục, vỡ TC, RBN, rau cài răng lược, rối loạn đông máu... Chính vì vậy, muc tiêu nghiên cứu là: Nghiên cứu môt số yếu tồ liên quan đến chảy máu 24 giờ sau đẻ đường âm đạo tại bệnh viện Phụ sản Hà Nội.

\section{II. ĐỐI TƯỢNG VÀ PHƯƠNG PHÁP NGHIÊN CỨU}

\section{1. Đối tượng nghiên cứu:}

2.1.1. Tiêu chuẩn lựa chọn đối tượng nghiên cứu

Tất cả các sản phụ được chẩn đoán CMSĐ 24h đường âm đạo đáp ứng các điều kiện sau:

- Tuổi thai từ 22 tuần trở lên

- Sau đẻ 24h đường âm đạo.

- Lượng máu mất sau sổ thai $\geq 500$ ml, hoặc có ít nhất 1 trong các tiêu chuẩn:

+ Phải truyên máu điều trị

+ Lượng máu mất ghi trong hồ sơ $\geq 500 \mathrm{ml}$

+ Phải cắt TC cầm máu

- Thời gian xuất hiện chảy máu trong vòng 24h đầu sau đẻ đường ầm đạo.

\subsubsection{Tiêu chuẩn loại trừ đối tượng} nghiên cứu

- Các bệnh máu đã được biết từ trước.

- Thời gian chảy máu sau đẻ >24h

Hồ sơ bệnh án không ghi chép rõ ràng, đầy đủ thông tin.

\subsection{Phương pháp nghiên cứu:}

2.2.1. Thiết kế nghiên cứu: Sử dụng phương pháp hồi cứu

2.2.2. Cỡ mấu và cách chon mẫu: Áp dụng phương pháp chọn mẫu thuận tiện; chọn tất cả các sản phụ được chẩn đoán CMSĐ 24h đường âm đạo được điều trị tại BVPSHN 
2.3. Thời gian và địa điểm nghiên cứu: Bệnh viện Phụ sản Hà Nội, từ tháng 1 năm 2019 tới hết tháng 12 năm 2020

2.4. Xử lý số liệu: Số liệu được phân tích bằng SPSS 20.0

2.5. Vấn đề đạo đức trong nghiên cứu: Tất cả các $B N$ đều được giải thích kĩ, hiểu về tình trạng bệnh của mình, tự nguyện tham gia vào nghiên cứu, có thể rời khỏi nghiển cứu bất cứ khi nào. Toàn bộ những thông tin cá nhân của các đối tượng tham gia nghiên cứu đều được bảo mật tuyệt đối, chỉ sự dụng vào mục đích nghiên cứu.

\section{KẾT QUẢ NGHIÊN CứU}

3. 1. Tỷ lệ chung chảy máu sau đẻ 24 giờ đường âm đạo tại Bệnh viện Phụ sản Hà Nội trong hai năm 2019-2020

Bảng 1. Tỷ lề chung CMSĐ đường âm đạo tại BVPSHN 2019-2020

\begin{tabular}{|c|c|c|c|}
\hline \multirow{2}{*}{ Năm } & \multicolumn{2}{|c|}{ Số trường hợp CMSÐ } & \multirow{2}{*}{ Tỷ lệ } \\
\cline { 2 - 3 } & $\begin{array}{c}\text { Số sản } \\
\text { phụ (n) }\end{array}$ & Tổng số & $\mathbf{( \% )}$ \\
\hline 2019 & 57 & 18821 & 0,30 \\
\hline 2020 & 41 & 15800 & 0,26 \\
\hline Tống & $\mathbf{9 8}$ & $\mathbf{3 4 6 2 1}$ & $\mathbf{0 , 2 8}$ \\
\hline
\end{tabular}

Nhânn xét: Tai bênh viện phu sản Hà Nội, số lượng sản phụ đẻ thường năm 2019 cao hơn số sản phụ năm 2020. Tỷ lệ sản phụ có chảy máu sau đẻ năm 2019 cao hơn tỷ lê sản phụ chảy máu sau đẻ năm 2020 (0,30 so với 0,26).

3.2. Số lân đẻ của sản phụ và chảy máu sau đẻ Bảng 2. Liên quan giữa CMSA và số lần đẻ

\begin{tabular}{|c|c|c|c|c|c|c|}
\hline \multirow{3}{*}{ Số lân đẻ } & \multicolumn{4}{|c|}{ CMSÐ } & \multirow{2}{*}{\multicolumn{2}{|c|}{ Tổng số }} \\
\hline & \multicolumn{2}{|c|}{ Năm 2019} & \multicolumn{2}{|c|}{ Năm 2020} & & \\
\hline & $\mathbf{n}$ & $\%$ & $n$ & $\%$ & $\mathbf{n}$ & $\%$ \\
\hline Con so & 18 & 31,6 & 14 & 34,1 & 32 & 32,6 \\
\hline Con ra & 39 & 68,4 & 27 & 65,9 & 66 & 67,4 \\
\hline Tống số & 57 & 100 & 41 & 100 & 98 & 100 \\
\hline
\end{tabular}

Nhân xét: Năm 2019 số sản phụ chảy máu sau đẻ sinh con rạ chiếm tỷ lệ cao hơn so với số sản phụ sinh con so (lần lượt là 68,4\% và 31,6\%). Năm 2020 cũng cho kết quả tương tự, với tỷ lệ sinh con ra ở sản phụ CMSĐ là $65,9 \%$ và tỷ lê sinh con so là $34,1 \%$.

3.3. Trong lượng thai và chảy máu sau đẻ

Bảng 3. Liên quan giứa chảy máu sau đẻ và trọng lượng thai

\begin{tabular}{|c|c|c|c|c|c|c|}
\hline \multirow{2}{*}{$\begin{array}{c}\text { Trọng lượng } \\
\text { thai }(\mathbf{g r})\end{array}$} & \multicolumn{4}{|c|}{ CMSÐ } & \multicolumn{2}{c|}{ Tổng số } \\
\cline { 2 - 7 } & $\mathbf{n}$ & $\mathbf{\%}$ & $\mathbf{n}$ & $\mathbf{\%}$ & $\mathbf{n}$ & $\mathbf{\%}$ \\
\hline$\leq 3500 \mathrm{~g}$ & 34 & 59,6 & 25 & 61,9 & 59 & 60,2 \\
\hline$>3500 \mathrm{~g}$ & 23 & 40,4 & 16 & 39,0 & 39 & 38,8 \\
\hline Tống sốn & $\mathbf{5 7}$ & $\mathbf{1 0 0}$ & $\mathbf{4 1}$ & $\mathbf{1 0 0}$ & $\mathbf{9 8}$ & $\mathbf{1 0 0}$ \\
\hline p & \multicolumn{3}{|c|}{$>0,05$} \\
\hline
\end{tabular}

Nhận xét: Năm 2019 và 2020 số sản phụ có thai nhi từ 3500gr trở xuống chiếm tỷ lệ cao hơn số sản phụ có thai nhi trên 3500 gram ( $59,6 \%$ so với 40,4\%) và (61,9\% so với $39,0 \%)$.

3.4. Liên quan giữa thời điểm chảy máu và đờ tử cung

Bảng 4. Liên quan giữa thời điểm chảy máu và đờ tử cung

\begin{tabular}{|c|c|c|c|c|c|c|}
\hline \multirow{3}{*}{ Thời điểm chảy máu } & \multicolumn{4}{|c|}{ CMSÐ do ĐTC } & \multirow{2}{*}{\multicolumn{2}{|c|}{ Tổng số }} \\
\hline & \multicolumn{2}{|c|}{ Năm 2019} & \multicolumn{2}{|c|}{ Năm 2020} & & \\
\hline & $\mathbf{n}$ & $\%$ & $\mathbf{n}$ & $\%$ & $\mathbf{n}$ & $\%$ \\
\hline$\leq 2$ giờ & 39 & 97,5 & 29 & 93,5 & 68 & 95,7 \\
\hline $2-6$ giờ & 1 & 2,5 & 2 & 6,5 & 3 & 4,3 \\
\hline $6-24$ giờ & 0 & 0 & 0 & 0 & 0 & 0 \\
\hline Tống số & 40 & 100 & 31 & 100 & 71 & 100 \\
\hline $\mathrm{p}$ & & & & & & \\
\hline
\end{tabular}

Nhận xét: Trong tổng số 98 sản phụ tham gia nghiên cứu, ghi nhận 71 sản phụ có nguyên nhân chảy máu sau đẻ là đờ tử cung. Trong đó phần lớn sản phụ có thời điểm chảy máu là dưới 2 giờ, chiếm tỷ lệ 95,7\% (68/71 trường hợp), không ghi nhận sản phụ nào có thời điểm chảy máu từ 6 - 24 giờ sau đẻ.

- Có 40 sản phụ trong năm 2019 găp tình trạng đờ tử cung, trong đó chỉ có 1 trường hợp chảy máu trong khoảng 2 - 6 giờ (chiếm 2,5\%), số còn lại đều bị chảy máu dưới 2 giờ (chiếm 97,5\%). 
- Năm 2020 ghi nhận 31 sản phụ bị đờ tử cung, trong đó 29 ca chảy máu dưới 2 giờ sau đẻ (chiếm 93,5\%), 2 ca chảy máu sau khoảng 2 - 6 giờ (chiếm 6,5\%).

\section{BÀN LUÂ̂N}

Nghiên cứu hồi cứu tại BVPSHN trong hai năm 2019-2020, năm 2019 có 57 trường hợp chiếm 0,3\%. Năm 2020 có 41 trường hợp, chiếm $0,26 \%$. Tỷ lệ chung của 2 năm là $0,28 \%$.

Nhiều nghiên cứu ở cùng đia điểm nghiên cứu là BVPSTW nhưng ở các thời kì khác nhau cho thấy tỉ lệ CMSĐ không giảm, mặc dù cơ sở vật chất tốt hơn, đội ngũ y bác sĩ có kinh nghiệm nhưng đây đều là tuyến cuối của cả nước về chuyên ngành sản khoa nên số lượng bệnh nhân đều tăng hàng năm ${ }^{2,3}$. Chứng tỏ rằng đầy là một thách thức cần nghiên cứu và giải quyết tiếp. Trong nghiên cứu của chúng tôi tỉ lệ này giảm qua 2 năm 2019 - 2020, tuy sự thay đổi này chưa có ý nghĩa thống kê (Bảng 1) nhưng cũng đã phản ánh phần nào sự thay đổi cơ sở vật chất, đội ngũ y bác sĩ được trau dồi kinh nghiệm tốt hơn để tiên lượng cũng như xử trí sớm, đúng lúc các trường hợp có nguy cơ CMSĐ.

Ngoài ra, sự khác nhau về tỷ lệ CMSĐ giữa các nghiên cứu ở các địa phương khác nhau và sự khác nhau của các nghiên cứu ở ngay cùng địa phương, địa điểm nhưng khác về thời gian thực hiện có thể giải thích là do những tiêu chuẩn lựa chọn hồ sơ bệnh án, bệnh nhân nghiên cứu khác nhau. Có thể thấy các nghiên cứu hồi cứu chịu ảnh hưởng và sai số rất nhiều của sự ghi chép đầy đủ hay không của y bác sỹ khi tổng kết điêu trị. Trong thực tế lâm sàng nhiều tác giả cho rằng số lượng máu mất nhiều hơn nhiều so với số ghi trong hồ sơ bệnh án.

Sự khác biệt này sẽ giảm đi đáng kể nếu ta tiến hành nghiên cứu tiến cứu và do cùng một nhóm tác giả thực hiện và đưa ra những tiêu chuẩn lựa chọn cụ thể, thống nhất và hồ sơ được lựa chọn tốt nhất là được thông qua bởi một nhóm các nhà lâm sàng.

Qua bảng 2 cho thấy tỷ lệ CMSĐ gặp ở người con rạ nhiều hơn ở người con so. Theo Trần Chân Hà ${ }^{3}$ thì nguy cơ này là gấp 2 lần, còn theo Hứa Thanh Sơn ${ }^{5}$ là 2,5 lần. Theo Phạm Văn Chung ${ }^{1}$ tỷ lệ CMSĐ ở người mang thai con rạ $>1,94$ lần so với ở người mang thai lần đầu. Người sinh đẻ nhiều lần làm cho chất lượng cơ tử cung kém đi, là yếu tố gây nên đờ tử cung dẫn tới hậu quả CMSĐ. CMSĐ ở con so đa phần gặp trong các trường hợp thai to đờ tử cung hoặc thai nhỏ sổ nhanh.
Năm 2019, số sản phụ có thai nhi từ 3500gr trở xuống chiếm tỷ lệ cao hơn số sản phụ có thai nhi trên 3500 gram (59,6\% so với $40,4 \%$ ). Năm 2020, số sản phụ có thai nhi từ $3500 \mathrm{gr}$ trở xuống chiếm $61,9 \%$, cao hơn số sản phụ có thai nhi trên 3500 gram (chiếm 39,0\%). CMSĐ liên quan đến trọng lượng thai chủ yếu gặp ở thai to, sau đẻ đờ tử cung hoặc các trường hợp thai nhỏ sổ nhanh gây rách phức tạp dẫn đến CMSĐ.

Thời điểm phát hiện CMSĐ có ý nghĩa hết sức quan trọng. Nó liên quan đến tính mạng của sản phụ, thai nhi cũng như quá trình điểu trị. Càng phát hiện được CMSĐ sớm tiên lượng sản phụ càng tốt, việc xử trí CMSĐ càng đớn giản và có hiệu quả. Ngược lại CMSÐ phát hiện muộn thì sản phụ đã mất nhiều máu với số lượng lớn, tiên lượng sản phụ sẽ không tốt, gây ra những ảnh hưởng nghiêm trọng, thậm chí tử vong.

Bảng 4 cho thấy, thời điểm phát hiện CMSĐ có tỷ lệ cao nhất là sau sổ rau 0-2 giờ có tới 68 trường hợp, chiếm 70\%. Các nguyên nhân thường gặp ở thời điểm này chủ yếu là chảy máu do đờ từ cung. Các trường hợp đờ tử cung thường xuất hiện trước 6 giờ sau sổ rau, vì vậy cần theo dõi sản phụ kỹ trong khoảng thời gian này để phát hiện sớm tình trạng chảy máu. Theo Trần Chân Hà ${ }^{3}$ thời điểm phát hiện CMSĐ có tỷ lệ cao nhất là trong vòng $3 \mathrm{~h}$ với tỷ lệ $65,9 \%$. Theo Phạm Văn Chung ${ }^{1}$ cho thấy CMSĐ được phát hiện sớm trước $2 \mathrm{~h}$ chiếm tỷ lệ cao nhất trung bình là $91,1 \%$, theo Nguyễn Thị Dung ${ }^{2}$ tỷ lệ cao nhất $63,0 \%$ trong $2 \mathrm{~h}$ đâu.

Khác biệt giữa các nghiên cứu về thời gian chảy máu có thể giải thích do tiêu chuẩn chọn lựa bệnh án, sản phụ nghiên cứu khác nhau, cách chia các mốc thời gian khác nhau. Có thể thây các nghiên cứu hồi cứu chịu ảnh hưởng và sai số rất nhiều của sự ghi chép đây đủ hay không của các y bác sĩ tổng kết điều trị.

Sự khác biệt này sẽ giảm đi nếu ta nghiên cứu tiến cứu và do cùng một nhóm tác giả thực hiện và đưa ra tiêu chuẩn lựa chọn cụ thể, thống nhất và hồ sơ được lựa chọn tốt nhất là được thông qua bởi một nhóm các nhà lâm sàng.

\section{KẾT LUẬN}

Tỷ lệ chảy máu sau đẻ 24 giờ đường âm đạo tại Bệnh viện Phụ sản Hà Nội năm 2019 là 0,3\%, giảm xuống $0,26 \%$ trong năm 2020, tỷ lệ chung trong 2 năm là $0,28 \%$.

Một số yếu tố liên quan:

- Tỷ lệ sản phụ sinh con rạ có chảy máu sau đẻ cao hớn gấp 2 lần sản phụ sinh con so.

- Số sản phụ có thai nhi từ 3500gr trở xuống 
chiếm tỷ lệ CMSĐ cao hơn số sản phụ có thai nhi trên 3500 gram.

- Thời điểm chảy máu sau đẻ hay gặp nhất 02h chiếm khoảng 95\%.

\section{TÀI LIÊU THAM KHẢO}

1. Phạm Văn Chung. Nghiên cứu về tình hình chảy máu sau đẻ tại bệnh viện phụ sản trung ương trong 2 giai đoan 1998-1999 và 2008-2009. Luân văn tốt nghiệp bác sĩ nội trú, Trường Đại Học Y Hà Nô̂i. 2009.

2. Nguyễn Thị Dung, Nghiên cứu một số nguyên nhân và kết quả xử trí chảy máu sau đẻ tại BV Phụ sản Hà nối trong năm 2014, Luân văn Thạc sĩ Y học, Trường Đại học Y Hà Nội, Hà Nội. 2014.
3. Trân Chân Hà, Nghiên cứu tình hình chảy máu sau đẻ tai viên BVBMTSS trong 5 năm (1996 2000), Luận văn thạc sĩ Y học, Trường Đại học Y Hà Nội, Hà̀ Nội. 2001.

4. Tô Thi Thu Hằng, Nghiên cứu tình hình các bà mẹ lớn tuổi đẻ con so tại viện BV BMTSS từ năm 1996-2000, Luận văn Thiac sỹ Y học, Trường Đại hoc Y Hà Nôi, Hà Nô̂i. 2001

5. Hứa Thanh Sơn, Bùi Sương, Lưu Quốc Khải, "Xử trí tích cức giai đoan 3 cuốc chuyển da tại BV PSHN 1994-1999" 2000.

6. Tổ chức Y tế Thế giới (WHO), WHO recommendations for the prevention and treatment of postpartum haemorrhage, Publications of the World Health Organization Printed in Italy. 2012.

\section{CHI PHÍ TRỰC TIẾP ĐIỀU TRI UNG THƯ VÚ HER2 DƯƠNG TÍNH TẠI BẾNH VIẾN K NĂM 2020}

\section{Trần Văn Dũng*, Lưu Hồng Huy*, Nguyễn Đức Tuấn*}

\section{TÓM TẮT}

Mục tiêu nghiên cứu: Để xác định chi phí trực tiếp đîêu trị nội trú của bệnh nhân ung thư vú HER22 dương tính tại Bệnh viện K năm 2020. Đối tượng nghiên cứu: Hồ sơ 80 bệnh án của bệnh nhân được chẩn đoán ung thư vú HER2 dương tính và được điều trị nội trú tại Bênh viện $\mathrm{K}$ năm 2020, được lưu trữ trên phần mềm quản lý của Bệnh viện K. Phương pháp nghiên cứu: Nghiên cứu mô tả cắt ngang. Kêt quả và kết luân: Nghiên cứu cho thấy, đợt điều trị hiện tại, chi phí trực tiếp điêuu trị cho người bệnh ung thư vú HER2 dướng tính là khoảng 20.010.000 VNĐ vớl thấp nhất là 1.034.000 VND và cao nhất là 97.852 .000 VNĐ. Tỷ lệ bảo hiểm y tế chi trả là trên $60 \%$ trong số những người bệnh dùng bảo hiểm. Chi phí điều trị trực tiếp có xu hướng tăng khi giai đoạn bệnh tăng.

Từ khóa: HER2 dương tính, ung thư vú, chi phí điều trị trực tiếp.

\section{SUMMARY}

\section{DIRECT COST OF HER2-POSITIVE BREAST} CANCER TREATMENT AT K HOSPITAL 2020

Objective: To determine the direct cost of inpatient treatment of patients with HER2-positive breast cancer at K Hospital in 2020. Subject: Records of 80 patients' medical records, who were diagnosed with HER2 + breast cancer and treated at K Hospital in 2020. Data is stored on the management software of K Hospital. Method: A cross-sectional descriptive study. Result and conclusion: The study showed that the direct cost of treating HER2-positive breast

*Bênh viện $K$

Chịu trách nhiệm chính: Trần Văn Dũng

Email: dungtranvk1011@gmail.com

Ngày nhận bài: 14.9.2021

Ngày phản biên khoa hoc: 12.11.2021

Ngày duyệt bài: 19.11.2021 cancer patients in one session was 20.010.000 VND with the lowest of 1.034.000 VND and the highest cost of 97.852.000 VNĐ. Health insurance coverage is over $60 \%$ of total direct costs among insured patients. Direct treatment costs tend to increase as the stage of the disease increases.

Keywords: HER2-positive breast cancer, direct treatment costs.

\section{I. ĐẶT VẤN ĐỀ}

Ung thư vú là căn bênh ung thư phổ biến nhất của phụ nữ trên thế giới cũng như ở Việt Nam, đồng thời là nguyên nhân hàng đầu gây tử vong do ung thư ở nữ giới. Theo Cơ quan nghiên cứu ung thư quốc tế (IARC) ước tính năm 2020 có hơn 2 triệu ca ung thư vú mắc mới và gần 700.000 ca tử vong do ung thư vú trên toàn thế giới. Tại Việt Nam năm 2020 báo cáo gần đây cho thây có 182.563 ca mắc mới ung thư', trong đó tì lệ mắc mới ung thư vú đứng thứ ba với 21.555 ca, chiếm tỷ lệ $11,8 \%$. Tỉ lệ tử vong của ung thư vú ở nước ta đứng thứ ba với $9.345 \mathrm{ca}$, chiếm tỷ lệ $7,6 \%$ số ca tử vong do các loại ung thư [1].

Ung thư vú có HER2 dương tính (thụ thể yễu tố phát triển biểu mô 2- Human Epidermal growth factor Receptor 2) chiếm khoảng 15-20\% trong các loại ung thư vú, được xem là một trong những nhóm bệnh có tiên lượng xấu nhất và được xếp vào nhóm nguy cớ cao. Trong những năm gần đây, nhiêu phác đồ như trastuzumab cùng với paclitaxel hoăc docetaxel đã được áp dụng trong điều trị ung thư vú HER2 dương tính và mang lại nhiều kết quả tích cực về thời gian sống thêm của bệnh nhân. Tuy nhiên, tình trạng bệnh ung thư vú HER2 dương tính vẫn 